\title{
EKSISTENSI TARI POH KIPAH PADA MASYARAKAT LHOKSEUMAWE
}

\author{
Niza Vayatul Niza ${ }^{1}$, Yusnizar Heniwaty ${ }^{2}$ \\ Program Studi Pendidikan Tari, Fakultas Bahasa Dan Seni Universitas Negeri Medan \\ Jalan Willem Iskandar Pasar V Medan Estate 20221, Sumatera Utara-Indonesia \\ Email : ${ }^{1}$ nizavayatulniza18@gmail.com. ${ }^{2}$ yusnizarheni@yahoo.com
}

\begin{abstract}
This study is a study of the existence of Poh Kipah dance in Lhokseumawe community. In this discussion using the theories relating to the topic of research is the theory of existence.The method used in this research is qualitative research method. The population in this study as well as a research sample of artists and dancers. Data collection techniques include literature study, interview, observation, and documentation.Based on the research that has been done, the existence of Poh Kipah dance which is seen from three time span, first from 1959-1979, Poh Kipah dance at this time become the beginning of the show performed as entertainment on the implementation to commemorate the Prophet's Maulid and the Circumcision. Where in the past this dance only has some movements such as hitting the fan into the palm of the hand, tapping the fan handle to the floor palm. Music accompaniment using internal music in the form of poetry in chant by syeh and in addition to the fan tap. The pattern of the floor from the beginning of entry has been sitting on the stage, with male dancers who numbered eight or the whole peoples, the clothing was only wearing bay clothing and wearing a cap, where in the dance held in the field and on the yard of the mosque, the purpose of dance Inn as an entertainment event at the Prophet's Maulid event. Second from 1979-1999, Poh Kipah dance in this period nothing changed from its existence in because at this time there is no data or documents that are clear for this dance performance. Third 1999-present, in this period the existence of this dance has undergone several changes that can be seen from the addition of varied motion, the music has been changed with the addition of musical instruments serune kale and rapai, in the composition of the accompaniment, from the side of the dancer has included a female dancer In the composition of the dance, this event is still still encountered in the entertainment event Prophet's Maulid and Circumcision but now we have found also in festivals, and Culture Week of Aceh.
\end{abstract}

Keywords: Existence, Poh Kipah Dance In Lhokseumawe Society.

\section{PENDAHULUAN}

Indonesia merupakan negara yang kaya akan budaya dengan keanekaragaman suku bangsa, dan bahasa. Indonesia memiliki 34 provinsi dan beribu pulau yang tersebar dari Sabang sampai Merauke. Setiap provinsi yang ada di Indonesia memiliki ciri khas kebudayaannya masing-masing. Salah satu provinsi yang ada di Indonesia adalah provinsi Aceh.
Provinsi Aceh merupakan salah satu provinsi yang terletak di ujung pulau Sumatera, ngan kota Banda Aceh sebagai ibukota. Provinsi Aceh terbagi menjadi 18 kabupaten dan 5 kotamadya salah satunya kota Lhokseumawe. Kota Lhokseumawe ini berada di tengah-tengah jalur Timur Sumatera dan berada diantara kota Banda Aceh dan kota Medan, sehingga kota Lhokseumawe ini merupakan jalur vital distribusi dan perdagangan di Aceh. 
Secara etimologi Lhokseumawe berasal dari kata Lhok dan Seumawe. Dalam bahasa Aceh, Lhok dapat berarti dalam, teluk, palung, dan Seumawe bermaksud air yang berputarputar atau pusat mata air pada laut sepanjang lepas pantai Banda Sakti dan sekitarnya. Keberadaan kawasan ini tidak lepas dari kemunculan kerajaan Samudra Pasai sekitar abad ke-13, kemudian kawasan ini menjadi bagian dari kedaulatan kesultanan Aceh sejak tahun $1524 \mathrm{M}$.

Kota Lhokseumawe memiliki kebudayaannya sendiri. Sama halnya seperti provinsi-provinsi lainnya yang berada di Indonesia. Menurut Koentjaraningrat (2004:12), "Dalam arti yang sempit, kebudayaan adalah kesenian, sebaliknya dalam arti yang sangat luas kebudayaan yaitu seluruh total dan pikiran, karya, dan hasil karya manusia yang tidak berakar kepada nalurinya, karena itu hanya bisa dicetuskan oleh manusia sesudah suatu proses belajar". Karena demikian luasnya, maka guna keperluan analisa konsep kebudayaan itu perlu dipecah lagi ke dalam unsur-unsurnya. Unsurunsur kebudayaan yang meliputi: kesenian, ilmu pengetahuan, kepercayaan, moral, hukum, adat-adat istiadat, dan pembawaan lainnya yang diperoleh dari anggota masyarakat.

Kesenian merupakan ekspresi dan kreativitas dari manusia yang dihasilkan melalui gerak, bunyi, gambar, atau sesuatu yang dapat digunakan oleh manusia itu sendiri. Kesenian juga merupakan warisan yang tidak boleh dilupakan, melainkan harus dikembangkan karena dapat menjadi ciri khas dari suatu daerah tersebut. Kesenian biasa digunakan dalam ritual, upacara adat, hiburan, dan pertunjukan sehingga kesenian itu sendiri tidak lepas dari aktivitas masyarakat.

Kesenian sebagai salah satu unsurunsur kebudayaan merupakan tiang yang menopang keberadaan masyarakat dalam berbagai upacara yang terdapat ditengah-tengah masyarakat. Kesenian tersebut terbagi atas seni musik, seni rupa, seni tari, seni sastra dan lain sebagainya. Salah satu seni tari yang berada di kota Lhokseumawe adalah tari Poh Kipah.

Tari Poh Kipah adalah tari kontradisi kreasi yang tahun 1959 yang ada di kota Lhokseumawe yang diwariskan secara turuntemurun oleh masyarakat Aceh yang ada Lhokseumawe. Tari Poh Kipah ini ditarikan secara duduk berbanjar dengan gerakan memukul kipas, yang sewaktu- waktu kipas tersebut dipukul dilantai, pinggang serta ditelapak tangan sesuai dengan ritme yang diinginkan dengan pola selang-seling ataupun serempak. Tari Poh Kipah ini hampir sama dengan tarian saman tari Poh Kipah ini menggunakan level-level seperti sedang rendah dan tinggi dan mimiliki syeh yang melantunkan syairnya.

Tari Poh Kipah ini merupakan tarian yang menunjukan gerakan-gerakan memukul kipas dengan ritme yang unik dan beragam. Poh Kipah memiliki arti memukul kipas karena properti yang digunakan adalah kipas yang terbuat dari pelepah pinang dan tidak boleh dijemur. Kipas ini terdiri dari 3 atau 4 lapis pelepah sehingga menimbulkan bunyi nyaring 
dengan berbagai tepukan bervariasi sesuai dengan irama gerak dan lagu yang dibawakan.

Musik iringan yang digunakan dalam tari Poh Kipah ini yaitu musik internal, berupa syair-syair dan shalawat nabi berisi tentang pesan-pesan ajaran agama Islam yang dinyannyikan langsung oleh penari. Tempo musik tari Poh Kipah ini menggunakan tempo sedang. Selain syair yang dinyanyikan langsung oleh penari musik iringan Poh Kipah ini juga berasal dari tepukan kipas yang diketukan dilantai dan ditangan.

Berdasarkan observasi awal penulis mendapatkan informasi dari narasumber bahwasanya tari Poh Kipah ini pada awalnya diciptakan oleh Almarhum Yusrizar pada tahun 1959. Tari ini pada mulanya hanya terdapat di kota Banda Aceh dan cepat menyerbar kesetiap kabupaten dan kota lainnya diseluruh Aceh. Tari Poh Kipah ini dimainkan oleh kaum lelaki di meunasah saat peringatan maulid nabi besar Muhammad SAW dan sunat Rasul, dengan jumlah penari ganjil maupun genap tergantung situasi pentas, namun seiring berjalannya waktu, tarian ini berkembang tidak hanya ditarikan diacara maulid nabi saja, tetapi tari ini sudah ditampilkan di acara-acara lainya seperti pekan kebudayaan Aceh dan acara-acara lainya, saat ini kaum perempuan sudah boleh menarikanya. Selain perkembangan tari Poh Kipah ini juga dapat dilihat dari syair dan musik iringan yang sudah memasukan iramairama dalam pertunjukanya seperti irama dangdut dan sebagainya. Walaupun tari Poh Kipah ini telah mengalami perkembangan akan tetapi tari ini tetap eksis dan masih tetap ditampilkan pada acara-acara di Aceh. Melihat perkembangan tari Poh Kipah ini, penulis tertarik untuk meneliti tarian ini dengan judul

\section{"Eksistensi Tari Poh Kipah Pada} Masyarakat Lhokseumawe“.

Untuk meneliti dan membahas tentang eksistensi tari Poh Kipah pada masyarakat Lhokseumawe, maka penulis menggunakan teori eksistensi menurut Abidin (2007:16), "Eksistensi adalah proses yang dinamis, suatu "menjadi" atau "mengada". Ini sesuai dengan asal kata eksistensi itu sendiri, yakni existere yang artinya keluar dari, "melampaui" atau "mengatasi".

Sesuai dengan judul penelitian (Eksistensi Tari Poh Kipah Pada Masyarakat Lhokseumawe) maka penelitian dilaksanakan didusun kampung Kramat kampung Simpang Empat Kecamatan Banda Sakti, Lhokseumawe. Waktu penelitian dilaksanakan pada Oktober sampai dengan Desember 2017. Populasi dalam penelitian ini adalah beberapa tokoh-tokoh adat masyarakat dan seniman-seniman yang mengerti tentang tari Poh Kipah.

Sampel dalam penelitian ini adalah tokoh adat dan seniman/ masyarakat sekaligus penari yang mengetahui tentang tari Poh Kipah. Selanjutnya untuk teknik pengumpulan data yang dilakukan adalah sebagai berikut: 1). Observasi, 2). Wawancara, 3).Dokumentasi, 4). Studi Kepustakaan.

Begitu juga dalam dalam Teknik pengumpulan data ini dilakukan setelah data terkumpul lalu keseluruhan data 
dikelompokkan sesuai dengan permasalahan yang diangkat, setelah itu menganalisis secara sistematis dengan menggunakan metode strategi analisis kualitatif kedalam bentuk tulisan artikel/ jurnal ilmiah.

\section{HASIL DAN PEMBAHASAN}

Menurut sejarahnya tari Poh Kipah ini diciptakan oleh almarhum Yusrizar yang lahir di Banda Aceh pada 23 Juli 1937 dan beliau menciptakan tarian ini di tahun 1959. Pada mulanya tari Poh Kipah ini hanya terdapat di kota Banda Aceh dan dengan begitu cepatnya tari ini menyebar ke setiap kabupaten dan kota lainnya di seluruh Aceh.

Secara etimologi, pengertian Poh Kipah adalah memukul kipas, Poh Kipah ini adalah tari tradisional yang ditarikan secara berkelompok yang terdiri sekitar delapan sampai sepuluh orang atau lebih yang disesuaikan dengan seberapa besarnya pentas.

Tari Poh Kipah ini ditarikan secara duduk berbanjar atau selang seling, dengan menunjukan gerakan memukul kipah (kipas), dan sewaktu-waktu kipas tersebut dipukul di lantai, pinggang serta telapak tangan, tetapi ditelapak tangan pula yang sering dipukul, dan tarian ini menggunakan level-level seperti level rendah, sedang dan tinggi dan memiliki syeh yang melantunkan syairnya.

Tari Poh Kipah ini mengandung makna dan pesan-pesan keagamaan dan pembangunan yang terkandung didalam syair tarian tersebut yaitu tentang bagaimana menjalani kehidupan. Seperti dalam pemahaman masyarakat
Lhokseumawe tentang hidup bahwa, "nyawa kita ini hanya sesaat tuhan kasih, dan hidup di dunia ini tidak akan kekal abadi jadi kita hidup tidak boleh sombong karena harta, jabatan serta kedudukan tidak akan bisa di bawa mati serta tidak menjadi penyelamat kita di akhirat, hanya amal dan kain kafan serta tikar satu lapislah yang kita bawa mati. Jadi hidup di dunia ini ingatlah tuhan dan berbaktilah kepadanya. Mengikuti perintahnya serta menjauhkan laranganya".

Tari Poh Kipah merupakan tari kreasi yang mentradisi setelah mengalami proses panjang untuk menjadi tari tradisi dengan terus menyesuaikan diri sesuai zaman. Tari Poh Kipah memperkaya kebudayaan masyarakat Aceh, yang juga akan menambah kekayaan kebudayaan nasional. Berbagai upaya yang telah dilakukan masyarakat di Aceh untuk melestarikan tarian ini, seperti dengan menggelarkan berbagai pementasan dan dokumentasi melalui foto dan video.

\section{Proses Pelaksanaan Tari Poh Kipah}

Proses pelaksaaan Poh Kipah ini dilaksanakan pada acara maulid nabi, pada saat selesai pembacaan Ayat Suci Alqur'an dan biasanya tarian ini di dilaksanakan pada malam hari setelah menunaikan shalat Isya. Tarian ini di tarikan oleh laki-laki yang di tentukan oleh sanggar atau kelompak dari pada tari tersebut. Mereka belajarnya memang sudah merupakan penari-penari yangg sudah mendapatkan latihan khusus untuk tarian ini, setelah mendapatkan baru dilaksanakan, ditunjuklah mereka sebagai wakil dari pada masyarakat kampung dan 
biasanya untuk pertunjukan tari Poh Kipah yang biasanya ditarikan oleh delapan, sepuluh atau lebih. Hal ini disebabkan karena agar masyarakat dengan berbondong-bondong datang untuk sama-sama mendengarkan dakwah yang disampaikan oleh tengku atau ulama. Dengan hadirnya tari Poh Kipah dilaksanakan dengan kesepakatan antara penyelenggara dengan kelompok tarian apabila kesepakatan terjadi maka tari Poh Kipah dapat dilaksanakan bisa pada siang hari, bisa malam hari.

\section{Bentuk Penyajian Tari Poh Kipah Pada} Masyarakat Lhokseumawe

\section{2.a. Gerak}

Dalam susunan penyajian tari Poh Kipah ini terdapat beberapa motif gerak yaitu :

- Duduk bersimpuh dengan posisi badan sedikit miring kekiri mengikuti arah tangan, tangan kanan memegang kipas lalu memukulnya ke tangan kiri dengan keadaan telapak tangan terbuka.

- Gerak hormat.

- Duduk bersimpuh badan membungkuk kemudian tangan kanan memegang gagang kipas lalu ujung gagang kipas diketukkan ke lantai, tangan kiri dikebelakangkan di belakang bergantian, kipas di arahkan ke belakang sebelah kanan dan ujung kipas di ketukkan ke lantai, sedangkan posisi tangan kiri direntangkan ke arah kiri dengan bentuk diagonal, posisi badan sedikit miring mengikuti arah kipas.

- Duduk bersimpuh memukul kipas arah kipas kekanan dan kekiri secara bergantian, posisi badan mengikuti efek kipas yang dipukul dengan arah ke kanan dan kekiri.

- Duduk bersimpuh tangan kanan memegang kipas dengan memutarnya di atas tangan kiri.

\section{2.b. Properti}

Properti yang digunakan dalam tari ini adalah kipas yang dijalin khusus yang dibuat dari pelepah pinang dalam bahasa Aceh disebut siteuk. Kipas ini terdiri dari tiga atau empat lapis pelepah pinang bahkan lebih, dimana pelepah ini tidak boleh dijemur hanya boleh di anginkan-anginkan saja, sehingga ketika ditepuk akan mengeluarkan bunyi yang nyaring tapi enak didengar dan bunyi yang dikeluarkan bervariasi sesuai dengan irama gerak dan lagu yang dibawakan.

\section{2.c. Iringan atau Musik.}

Iringan atau musik yang mengiringi tari Poh Kipah ini adalah berupa syair yang dibawakan oleh seorang syeh yang kemudian di ikuti atau disahuti oleh penari-penari sambil menyanyi. Bunyi-bunyi lain yang keluar untuk mengiringi tari ini yaitu bunyi dari properti kipas yang dipikul ke telapak tangan. Perkembangan dari iringan musik tarian ini sudah ditambahkan dengan alat musik berupa rapa'i dan serune kale.

\section{2.d. Tata Rias dan Busana}

Tari Poh Kipah menggunakan riasan cantik untuk penari wanitanya, sedangkan penari laki-laki tidak ditentukan riasanya. Busana untuk tarian laki-laki tidak diharuskan 
memakai adat Aceh tetapi sesuai keinginan penari dan biasanya memakai baju yang sopan seperti baju teluk belanga serta memakai peci itu sewaktu dipertujukan di acara maulid Nabi sedangkan kalau di acara festival lainya biasanya penari wanita memakai busana tarian Aceh lazimnya seperti tarian lainnya.

\section{2.e. Pola Lantai}

Pola lantai pada tari ini prinsipnya hampir sama dengan tarian Aceh lainya yaitu dengan duduk berbanjar dan sewaktu berubah tempat ada yang kebelakang dan ada yang di depan.

\section{2.f. Tempat Pertunjukan}

Biasanya seni tari Poh Kipah bisa dilakukan dimana saja, dilapangan, di pendopo, maupun lapangan terbuka. Tari ini tidak membutuhkan arena pentas yang khusus.

\section{Eksistensi Tari Poh Kipah Pada} Masyarakat Lhokseumawe

1. Tahun 1959-1979Poh Kipah pada masa ini menjadi awal dari pertunjukan yang dilakukan sebagai hiburan pada acara memperingati maulid nabi dan Sunat Rasul yang mana tarian ini hanya memiliki beberapa gerakan seperti memukul kipas ke telapak tangan, mengetuk gagang kipas kelantai. Musik iringan menggunakan musik internal berupa syair yang dilantunkan oleh syeh dan ditambah dengan tepukan kipas. Pola lantai dari awal masuk sudah duduk bersimpuh di atas pentas, dengan penari laki-laki yang berjumlah delapan atau sepeluh orang, busananya pun hanya memakai baju teluk belanga dan memakai peci, tempat diselenggarakan tarian ini dilaksanakan di lapangan serta halaman mesjid, tujuan tarian ini sebagai acara hiburan diacara maulid nabi.

2. Tahun 1979-1999, tari Poh Kipah di periode ini tidak ada yang berubah dari eksistensinya dikarenakan pada masa ini belum terdapatnya data atau dokumen yang jelas untuk pertunjukan tarian ini.

3. Tahun 1999-sekarang, di periode ini eksistensi tarian ini sudah mengalami beberapa perubahan yang dapat dilihat dari adanya penambahan gerak yang bervariasi, musik iringanya sudah mengalami perubahan dengan penambahan alat musik serune kale dan rapa'i, dalam komposisi iringan, dari sisi penari sudah menyertakan penari perempuan dalam komposisi tari, acara ini tetap masih kita jumpai diacara hiburan maulid nabi dan Sunat Rasul tetapi sekarang sudah kita temukan juga diacara festival, dan Pekan Kebudayaan Aceh.

\section{PENUTUP}

\section{Kesimpulan}

Dari hasil pembahasan yang telah dipaparkan, maka dapat ditarik beberapa kesimpulan bahwa eksistensi tari Poh Kipah ini dapat dilihat dari tiga rentangan waktu yaitu sebagai berikut :

4. Tahun 1959-1979Poh Kipah pada masa ini menjadi awal dari pertunjukan yang dilakukan sebagai hiburan pada acara 
memperingati maulid nabi dan Sunat Rasul yang mana tarian ini hanya memiliki beberapa gerakan seperti memukul kipas ke telapak tangan, mengetuk gagang kipas kelantai. Musik iringan menggunakan musik internal berupa syair yang dilantunkan oleh syeh dan ditambah dengan tepukan kipas.

Pola lantai dari awal masuk sudah duduk bersimpuh di atas pentas, dengan penari laki-laki yang berjumlah delapan atau sepeluh orang, busananya pun hanya memakai baju teluk belanga dan memakai peci, tempat diselenggarakan tarian ini di laksanakan di lapangan serta halaman mesjid, tujuan tarian ini sebagai acara hiburan di acara Maulid Nabi.

5. Tahun 1979-1999, tari Poh Kipah di periode ini tidak ada yang berubah dari eksistensinya dikarenakan pada masa ini belum terdapatnya data atau dokumen yang jelas untuk pertunjukan tarian ini.

6. Tahun 1999-sekarang, di periode ini eksistensi tarian ini sudah mengalami beberapa perubahan yang dapat dilihat dari adanya penambahan gerak yang bervariasi, musik iringanya sudah mengalami perubahan dengan penambahan alat musik serune kale dan rapa' $i$, dalam komposisi iringan, dari sisi penari sudah menyertakan penari perempuan dalam komposisi tari, acara ini tetap masih kita jumpai di acara hiburan maulid nabi dan Sunat Rasul tetapi sekarang sudah kita temukan juga di acara festival, dan Pekan Kebudayaan Aceh.

\section{Saran}

Berdasarkan hasil penelitian ini, maka peneliti memberikan saran sebagai berikut:

1. Pemerintah Kabupaten Kota Lhokseumawe melalui Dinas Kebudayaan dan Pariwisata hendaknya lebih memperhatikan keberadaan tari Poh Kipah yang merupakan salah satu kesenian budaya daerah. Upaya tersebut dapat dilakukan dengan seringnya menampilkan tari Poh Kipah pada acaraacara yang berkaitan dengan tradisional yang ada di Provinsi Aceh.

2. Agar masyarakat khususnya di Kabupaten Kota Lhokseumawe mengenal tari Poh Kipah, tetap menjaga dan melestarikan nilainilai yang terkandung dalam kesenian tersebut.

3. Seniman pada umumnya agar lebih mengembangkan kesenian tarian terutama tari Poh Kipah supaya lebih menarik generasi muda untuk mempelajari tari tersebut sebagai salah satu kekayaan budaya di Kota Lhokseumawe.

\section{DAFTAR PUSTAKA}

Abidin, 2007. Ekonomi Pembangunan. Jakarta: PT. Grafindo persada.

Abidin, Zainal. 2007. Analisis Eksistensial. Jakarta: PT. Raja Grafindo Persada.

Arikunto, S. 1998. Prosedur Penelitian Suatu Pendekatan Praktik. Jakarta: PT. Rineka Cipta.

Athaillah dan Muchtar Djalal. 1980. Kesenian Tradisional Aceh. Jurnal

Djelantik, A.A.M. 1999. Estetika. Bandung. 
Halifudin Hani, 2012. Tips Memilih Tema Skripsi. Yogyakarta: DIVA Fress

Koenjraningrat, 2004. Kebudayaan Mentalitas dan Pembangunan. Jakarta: Gramedia.

Suzanne K Langer, 1988. Problem of Art. Terjemahan F. X. Widyanto. Bandung: Akademi Seni Tari Indonesia.

Margono S, 1997. Metodologi Penelitian Pendidikan Tari. Jakarta: PT Rineka Cipta.

Sal Murgianto, 1983. Koreografi Pengetahuan Dasar Komposisi Tari. Jakarta: (Direktorat Jenderal) Pendidikan dasar dan mencegah departemen pendidikan dan kebudyaan.

Pusat Pembinaan Bahasa, 1990. Kamus Besar Bahasa Indonesia. Jakarta: Balai Pustaka.

Anas Sudijono, 2008. Pengantar Statistik Pendidikan. Jakarta: Raja Grafindo Persada.

Nana Sudjana, 2005. Metode Statistika. Bandung: Tarsito 